\title{
Características epizootiológicas da infecção natural pelo vírus da cinomose canina em Belo Horizonte
}

\author{
[Natural canine distemper virus infection epizootiology characteristics in Belo Horizonte] \\ B.C. Martins ${ }^{1}$, B.B.J. Torres $^{2}$, M.B. Heinemann ${ }^{3}$, R.A. Carneiro $^{1}$, E.G. Melo ${ }^{1}$ \\ ${ }^{1}$ Escola de Veterinária - Universidade Federal de Minas Gerais - Belo Horizonte, MG \\ ${ }^{2}$ Escola de Veterinária e Zootecnia, Universidade Federal de Goiáis \\ ${ }^{3}$ Faculdade de Medicina Veterinária e Zootecnia - Universidade de São Paulo - São Paulo, SP
}

\begin{abstract}
RESUMO
O perfil epizootiológico da cinomose canina em Belo Horizonte é desatualizado e não alberga algumas características relevantes. Uma análise recente da distribuição do vírus em relação às características do hospedeiro e do meio ambiente associada aos principais sinais clínicos e achados laboratoriais são importantes para se adotarem medidas estratégicas para o controle da enfermidade. Objetivou-se, assim, determinar as características epizootiológicas da infecção pelo vírus da cinomose canina associada à variedade de sinais clínico-neurológicos e laboratoriais em Belo Horizonte, auxiliando no diagnóstico precoce da infecção e na diminuição das taxas de morbidade e mortalidade da doença. A avaliação do perfil epizootiológico de 90 cães revelou que a doença é mais frequente em animais adultos (um a seis anos de idade) e que não receberam vacinas conforme recomendado pelos protocolos. Os sinais clínicos extraneurais e neurais foram variados, com predomínio para manifestações gastrentérica e respiratória, mioclonia e déficit motor, respectivamente. O exame do fluido cérebro-espinhal demonstrou predomínio de proteinorraquia associada à pleocitose linfocítica. $\mathrm{O}$ teste de imunocromatografia para pesquisa de antígeno com amostras do fluido cerebroespinhal foi eficaz para identificar a doença em pacientes com sinais neurológicos, diferentemente das amostras do $s w a b$ conjuntival, que não devem ser utilizadas.
\end{abstract}

Palavras-chave: cinomose canina, perfil epidemiológico, sinais clínico-neurológicos, alterações laboratoriais

\begin{abstract}
The epizootiology profile of canine distemper in Belo Horizonte is outdated and does not harbor some important characteristics. A recent analysis of the virus distribution in relation to host and environmental characteristics associated with the main clinical signs and laboratory findings are important for adopting strategic measures to control the disease. The aim of this study was to determine the epizootiology characteristics of canine distemper virus infection associated with a variety of clinical and neurologic signs and laboratory findings in Belo Horizonte, helping to detect early infection and reduce morbidity and mortality rates. The evaluation of the epizootiology profile of 90 dogs revealed that the disease is more frequent in adult animals (1-6 years of age) and did not receive vaccines as recommended by the protocols. Extra neural and neural clinical signs were varied, with predominance for gastrointestinal and respiratory manifestations and myoclonus and motor deficit, respectively. Examination of the cerebrospinal fluid of 16 dogs showed a predominance of increase protein associated with lymphocytic pleocytosis. The immunochromatography test for antigen screening with samples of cerebrospinal fluid in 76 animals with neurological signs was effective in identifying the disease, unlike conjunctival swab samples, which should not be used.
\end{abstract}

Keywords: canine distemper, epidemiological profile, clinical-neurological signs, laboratory alterations

Recebido em 4 de fevereiro de 2019

Aceito em 15 de agosto de 2019

E-mail: bernardodcmartins@hotmail.com 


\section{INTRODUÇÃOO}

A cinomose canina (CC) é uma doença ocasionada por um Morbillivirus da família Paramyxoviridae, observada há mais de 250 anos, desde o surgimento das primeiras estirpes nos Estados Unidos (Panzera et al., 2015). Devido ao surgimento de novas estirpes, oriundas de mutações do gene $\mathrm{H}$, persiste como uma das principais doenças infecciosas letais, que acometem os cães no mundo inteiro, mesmo com a introdução de vacinas de vírus atenuado em meados de 1950 (Headley e Graça, 2000). O vírus infecta animais de qualquer idade, sexo e raça e resulta em uma variedade de sinais clínicos e neurológicos que podem ser manifestados isoladamente ou em associação, o que torna o diagnóstico clínico bastante desafiador (Appel, 1972). A maioria dos exames complementares é inespecífica, mas, quando associados às características epizootiológica da doença, contribuem para o diagnóstico clínico.

A imunocromatografia para detecção do antígeno é um método rápido amplamente utilizado para diagnóstico da CC. Apesar da indicação da utilização do esfregaço conjuntival, observou-se que esse tipo de amostra é pouco sensível em animais com sinais neurológicos associados ou não a sinais sistêmicos (Curti et al., 2012). Pereira (2010) demonstrou que o teste possui alta sensibilidade e especificidade na detecção do vírus da cinomose canina (CDV) em amostras de fluido cerebroespinhal (FCE) de animais com sinais neurológicos e/ou sistêmicos. No entanto, existe a necessidade de um estudo que compare a eficácia do teste utilizando-se diferentes amostras, do mesmo animal, em cães com sinais neurológicos, para que se possa definir qual amostra deve ser escolhida para o teste e se evitarem os falso-positivos.

A CC continua sendo uma doença viral de impacto socioeconômico no campo veterinário brasileiro devido aos altos custos de tratamentos, às falhas na imunização vacinal e ao sofrimento dos proprietários e dos animais (Headley et al., 2012). A infecção de animais vacinados é preocupante e cada vez mais constante. Associado a isso, não existe ainda terapia antiviral efetiva, sendo instituído apenas tratamento sintomático. Além disso, a diversidade socioeconômica das diferentes regiões brasileiras dificulta o estabelecimento das tendências epizootiológicas do CDV e do manejo da doença. Dessa forma, objetivou-se realizar um estudo para determinar as características epizootiológicas da infecção pelo CDV associada à variedade de sinais clíniconeurológicos e aos achados laboratoriais na cidade de Belo Horizonte, Minas Gerais, o que pode auxiliar no diagnóstico precoce da infecção e na diminuição das taxas de morbidade e mortalidade.

\section{MATERIAL E MÉTODOS}

Foi realizado um estudo clínico com cães, naturalmente infectados com o vírus da cinomose canina, atendidos no Hospital Veterinário, no período de 2012-2014, para caracterização da doença no município de Belo Horizonte. Nesse período foram avaliados centenas de animais com sinais suspeitos da infecção. Foram incluídos no experimento 90 animais, que foram positivos nos testes imunocromatográficos para detecção de antígeno (Cinomose $\mathrm{Ag}$ - Alere, Brasil), em amostras de swab conjuntival e/ou FCE. O projeto foi aprovado pela Comissão de Ética no Uso de Animais (Ceua) da UFMG, com o protocolo de número 32/2013.

Os dados epizootiológicos foram anotados e comparados em relação às variáveis de sexo (macho ou fêmea), idade [dois a quatro meses (janela imunológica), cinco a 11 meses (jovens), um a seis anos (adultos) ou acima de seis anos (idosos)], época do ano [meses quentes e úmidos (outubro a abril), meses frios e secos (maio a setembro)] e condição vacinal. Foram considerados com estado vacinal em dia os animais que receberam a primeira vacinação polivalente a partir dos dois até os quatro meses de idade, completando um protocolo inicial de três vacinas intervaladas a cada 21 dias, que receberam reforço anual e foram vacinados em clínicas veterinárias. Já os animais que não receberam as três doses iniciais e/ou o reforço anual e que não foram vacinados em clínicas veterinárias foram considerados com protocolo vacinal incompleto. Todos os sinais clínicos e neurológicos foram anotados no momento da apresentação dos pacientes.

Para comparação da eficiência do teste da imunocromatografia entre as amostras de raspado conjuntival e do FCE, foram avaliados 76 animais positivos no teste, que apresentaram 
sinais neurológicos acompanhados ou não de outros sinais clínicos. As amostras foram coletadas e processadas de acordo com a recomendação do fabricante.

O FCE de 16 animais, escolhidos aleatoriamente, foi coletado em frasco sem anticoagulante, para análise física (coloração e turbidez), quantitativa (concentração de proteínas, células nucleadas e hemácias) e citológica (distribuição de leucócitos e observação de outros tipos celulares e microrganismos). Amostras com mais de cinco células por $\mu \mathrm{L}$ foram consideradas com pleocitose, e as que apresentaram concentração de linfócitos acima de $50 \%$ foram classificadas com pleocitose linfocítica (Platt e Garosi, 2012). Além disso, o aumento de proteína foi considerado quando as amostras se apresentavam com índices acima de $20 \mathrm{mg} / \mathrm{dL}$. A observação de mais de uma hemácia foi suficiente para caracterizar um aumento da concentração de hemácias (Platt e Garosi, 2012).
Para as análises de contingência, foi utilizado o teste exato de Fischer para variáveis dicotômicas (sexo, época do ano, estado vacinal e teste de imunocromatografia) $(\mathrm{P}<0,001)$, e a distribuição de frequência do qui-quadrado para variáveis com mais de uma resposta (idade, sinais extraneurais, sinais neurológicos e alterações do fluido cerebroespinhal $) \quad(\mathrm{P}<0,05)$. Os dados foram analisados pelo pacote estatístico Graphpad prism 5 for Windows (GraphPad Software, La Jolla, CA, EUA).

\section{RESULTADOS E DISCUSSÃO}

Após estudo das características da infecção pelo CDV nos 90 cães positivos, foi possível estabelecer a distribuição da infecção viral de acordo com as características do hospedeiro e as condições ambientais (Tab. 1).

Tabela 1. Prevalência do vírus da cinomose canina em relação às variáveis sexo, idade, época do ano e estado vacinal, em 90 cães infectados naturalmente

\begin{tabular}{lll}
\hline Variáveis & & $\mathrm{N}=90(100 \%)$ \\
\hline Sexo & Macho & $43(47 \%)^{\mathrm{a}}$ \\
& Fêmea & $47(53 \%)^{\mathrm{a}}$ \\
& & \\
Idade & $2-4$ meses & $10(11 \%)^{\mathrm{a}}$ \\
& $5-11$ meses & $22(24 \%)^{\mathrm{b}}$ \\
& $1-6$ anos & $41(45 \%)^{\mathrm{c}}$ \\
& $>6$ anos & $17(19 \%)^{\mathrm{ab}}$
\end{tabular}

$\begin{array}{lll}\text { Época do ano } & \text { Meses quentes (outubro a abril) } & 46(51 \%)^{\mathrm{a}} \\ & \text { Meses frios (maio a setembro) } & 44(49 \%)^{\mathrm{a}}\end{array}$

$\begin{array}{lll}\text { Estado vacinal } & \text { Em dia } & 16(18 \%)^{\mathrm{a}} \\ & \text { Protocolo vacinal incompleto } & 74(82 \%)^{\mathrm{b}}\end{array}$

Valores seguidos de letras distintas, na variável analisada, diferem estatisticamente entre si pelo teste exato de Fischer para variáveis dicotômicas e pelo teste de qui-quadrado para variáveis com mais de uma resposta $(\mathrm{P}<0,001)$.

Quando se avaliaram os dados referentes ao sexo dos animais naturalmente infectados pelo CDV, $43(47 \%)$ eram machos, e $47(53 \%)$ fêmeas. Não houve diferença estatística significativa $(\mathrm{P}>0,05)$ nessa distribuição corroborando os achados de Headley e Graça (2000) e Headley e colaboradores (2012). Entretanto, Baumgärtner e colaboradores (1989) e Koutinas e colaboradores (2002) encontraram predominância da infecção em machos, o que, segundo Sonne e colaboradores (2009), pode estar relacionado ao maior número de animais desse gênero nos locais onde esses estudos foram realizados.

Quando se avaliaram os dados referentes à idade, observou-se que $10(11 \%)$ animais tinham entre dois e quatro meses de idade, 22 (24\%) entre cinco e 11 meses de idade, 41 (45\%) entre um e 
seis anos e 17 (19\%) acima dos seis anos. A maior incidência da infecção, na faixa etária de um a seis anos, foi estatisticamente significante, assim como a menor incidência nos animais entre dois e quatro meses $(\mathrm{P}<0,05)$. A média das idades foi de 44 meses (três anos e meio). Os grupos foram divididos arbitrariamente, na tentativa de abranger as quatro diferentes fases da vida de um cão, possibilitando melhor avaliação da progressão da doença em relação à faixa etária e com base nos dados da Tab. 2. Os dados tabulados relacionados à incidência da doença em relação à idade são controversos, já que não existe um padrão na distribuição da faixa etária nos diversos estudos, o que dificulta a comparação entre as pesquisas (Headley et al., 2012).

Tabela 2. Prevalência da cinomose canina em diversos modelos de distribuição em relação à idade dos animais infectados

\begin{tabular}{|c|c|c|c|c|c|c|c|c|c|c|c|c|c|c|c|}
\hline \multicolumn{2}{|c|}{$\begin{array}{l}\text { Gouveia } \text { et al. } \\
\text { (1987) }\end{array}$} & \multicolumn{2}{|c|}{$\begin{array}{l}\text { Headley e Graça } \\
(2000)\end{array}$} & \multicolumn{2}{|c|}{$\begin{array}{l}\text { Dezengrini et } \\
\text { al. }(2007)\end{array}$} & \multicolumn{2}{|c|}{$\begin{array}{l}\text { Silva et al. } \\
\text { (2007) }\end{array}$} & \multicolumn{2}{|c|}{$\begin{array}{l}\text { Hass et al. } \\
(2008)\end{array}$} & \multicolumn{2}{|c|}{$\begin{array}{l}\text { Silva et al. } \\
\text { (2009) }\end{array}$} & \multicolumn{2}{|c|}{$\begin{array}{l}\text { Sonne et al. } \\
\text { (2009) }\end{array}$} & \multicolumn{2}{|c|}{$\begin{array}{l}\text { Martins } \\
(2019)\end{array}$} \\
\hline $\begin{array}{l}\text { Idade } \\
\text { (anos) }\end{array}$ & $\begin{array}{l}\mathrm{P} \\
(\%)\end{array}$ & $\begin{array}{l}\text { Idade } \\
\text { (anos) }\end{array}$ & $\begin{array}{l}\mathrm{P} \\
(\%)\end{array}$ & $\begin{array}{l}\text { Idade } \\
\text { (anos) }\end{array}$ & $\begin{array}{l}\mathrm{P} \\
(\%)\end{array}$ & $\begin{array}{l}\text { Idade } \\
\text { (anos) }\end{array}$ & $\begin{array}{l}\mathrm{P} \\
(\%)\end{array}$ & $\begin{array}{l}\text { Idade } \\
\text { (anos) }\end{array}$ & $\begin{array}{l}\mathrm{P} \\
(\%)\end{array}$ & $\begin{array}{l}\text { Idade } \\
\text { (anos) }\end{array}$ & $\begin{array}{l}\mathrm{P} \\
(\%)\end{array}$ & $\begin{array}{l}\text { Idade } \\
\text { (anos) }\end{array}$ & $\begin{array}{l}\mathrm{P} \\
(\%)\end{array}$ & Idade & $\begin{array}{l}\mathrm{P} \\
(\%)\end{array}$ \\
\hline $0-2$ & 2,6 & $0-1,5$ & 62,8 & $<1$ & 14,3 & $0-1$ & 51,4 & $0-0,5$ & 9,1 & $<0,5$ & 34,3 & $0,2-0,5$ & 78,5 & $\begin{array}{l}2-4 \\
\text { meses }\end{array}$ & 11 \\
\hline \multirow[t]{3}{*}{ SE } & 4,7 & $>6$ & 6,4 & $3-5$ & 28 & & & $>6$ & 18,9 & 2 & 10 & $4-8$ & 3,9 & $\begin{array}{l}>6 \\
\text { anos }\end{array}$ & 19 \\
\hline & & & & $>5$ & 38,6 & & & SE & 16,7 & $3-4$ & 8,6 & & & & \\
\hline & & & & $\mathrm{SE}$ & 41,3 & & & & & $5-6$ & 8,6 & & & & \\
\hline
\end{tabular}

$\mathrm{P}$ (prevalência).

SE (sem especificação).

Tabela modificada de Headley et al. (2012).

* Dados do presente artigo.

Com isso, não são claras as conclusões sobre em qual faixa etária ou em qual fase da vida do animal a infecção é mais frequente. Historicamente, entende-se que a prevalência natural da cinomose canina é maior em cães imaturos, principalmente no período de janela imunológica (entre dois e quatro meses), quando os animais não produzem seus anticorpos em quantidades adequadas e a imunidade passiva transferida pelo colostro materno está em declínio (Krakowka e Koestner, 1976). Diferentemente do que se estipula, os dados do presente trabalho demonstraram maior ocorrência de CC em cães jovens (cinco a 11 meses) e adultos (um a seis anos) e menor incidência na fase de janela imunológica.

Há de se considerar que, em países onde alguns desses estudos foram realizados, a maioria dos animais jovens a adultos é vacinada, o que diminui consideravelmente a ocorrência da doença nessa faixa etária, diferentemente do Brasil, onde existem muitos cães não domiciliados e a porcentagem de animais vacinados é muito menor (Headley et al., 2009; Greene e Vandevelde, 2012; Day et al., 2016). Além disso, o surgimento de novas estirpes circulantes possibilita infecção, inclusive, de cães vacinados, o que pode aumentar a ocorrência da infecção em animais jovens/adultos, observada nos estudos mais recentes (Amude et al., 2006; Dezengrini et al., 2007).

A maioria dos animais $46(51 \%)$ deu entrada no hospital durante o período de meses quentes e úmidos comparado ao período de meses frios e secos 44 (49\%), mas não houve diferença estatística significativa $(\mathrm{P}>0,05)$ entre as duas frequências. Apesar de a ocorrência sazonal do CDV não ser bem definida, estudos demonstram maior incidência no período de meses frios (Headley e Graça, 2000). O CDV é pouco resistente ao ambiente, principalmente em temperaturas altas (Greene e Vandevelde, 2012). 
Com isso, esperava-se que, no período de meses frios, os casos de cães com CC fossem mais frequentes, devido ao maior tempo que esse vírus pode ficar ativo no ambiente. Além disso, temperaturas baixas podem resultar em imunossupressão por estresse, o que facilita a infecção, principalmente de neonatos (Headley e Graça, 2000). Acredita-se também que, nesse período em que o ar está mais seco, há maior possibilidade de dispersão das partículas virais, já que existe pouca umidade para que ocorra a precipitação dessas partículas. Um fator que pode ter contribuído para esses achados é que a região de Belo Horizonte não sofre variações extremas de temperaturas nos períodos de meses frios e quentes, como a região de Santa Maria (Headley e Graça, 2000) e dos países europeus (Martella et al., 2008), onde o inverno é rigoroso e as temperaturas podem atingir picos negativos.

Observou-se que $74(82 \%)$ animais, que foram diagnosticados com CC, estavam com protocolo vacinal incompleto, e 16 (18\%) com a vacinação em dia. Houve diferença estatística significativa $(\mathrm{P}<0,05)$ entre as duas distribuições. De fato, desde a introdução de vacinas em 1950, houve redução significativa do número de cães infectados, principalmente nos países desenvolvidos. No entanto, a CC continua sendo uma das principais doenças infecciosas no território brasileiro, mesmo em cães vacinados (Headley et al., 2012). É preocupante a ocorrência da infecção em $18 \%$ dos animais que estavam com os protocolos corretos de vacinação, indicando falha vacinal.

Estudos indicam que estirpes de campo isoladas em diversas regiões geográficas demonstraram diferenças genéticas no gene hemaglutinina, quando comparado às amostras vacinais (Iwatsuki et al., 1997; Panzera et al., 2012). No Brasil as informações moleculares das estirpes circulantes demonstram que as estirpes de campo pertencem à linhagem América do Sul I, diferentemente das estirpes vacinais, que pertencem à linhagem América I (Budaszewski et al., 2014). A variação genética observada entre as linhagens de campo e as estirpes vacinais deve ser considerada como um potencial fator para explicar as falhas vacinais (Panzera et al., 2012).

Todos os animais do presente estudo apresentaram, em algum momento, sinais clínicos, na maioria das vezes, inespecíficos e multifocais, referentes à proliferação do vírus nos sistemas respiratório, gastrentérico, dermatológico e/ou neurológico (Tab. 3, Tab. 4). Neste estudo, dos 90 animais estudados, 71 $(79 \%)$ apresentaram sinais extraneurais e 76 $(84,4 \%)$, sinais neurológicos. Desses, 57 (63\%) tiveram associação de sinais sistêmicos e neurológicos. O sinal clínico extraneural mais comumente observado com valor estatisticamente significativo $(\mathrm{P}<0,05)$ foi secreção ocular/nasal (63\%), provavelmente decorrente de uma ceratoconjuntivite seca, ou coinfecções, que resultaram em pneumonia intersticial ou broncopneumonia.

Tabela 3. Prevalência dos sinais clínicos extraneurais observados em 71 cães naturalmente infectados pelo vírus da cinomose canina

\begin{tabular}{ll} 
Sinal clínico & $\mathrm{n}=71(100 \%)$ \\
\hline Secreção nasal e ocular & $45(63 \%)^{\mathrm{a}}$ \\
Anorexia & $37(52 \%)^{\mathrm{a}}$ \\
Diarreia/Vômito & $37(52 \%)^{\mathrm{a}}$ \\
Dispneia/Tosse & $21(29 \%)^{\mathrm{b}}$ \\
Pústulas abdominais & $13(18 \%)^{\mathrm{b}}$ \\
Hiperqueratose de coxins & $5(7 \%)^{\mathrm{c}}$ \\
Hipertermia & $1(1 \%)^{\mathrm{c}}$ \\
\hline
\end{tabular}

Valores seguidos de letras distintas diferem estatisticamente entre si pelo teste de qui-quadrado. com valor de $\mathrm{P}<0,05$.

Os sinais extraneurais menos frequentes foram a hiperqueratose de coxins plantares $(7 \%)$ e a hipertermia. A primeira geralmente é manifestada quando os animais estão em fase neurológica, pois os queratinócitos são as últimas células, assim como a neuroglia, a serem infectadas pelo vírus (Greene e Vandevelde, 2012). No presente estudo, não se observou correlação positiva entre animais com sinais neurológicos e a hiperqueratose, visto que dos 76 animais que manifestaram sinais neurológicos, apenas cinco também tiveram hiperqueratose dos coxins. A hipertermia na infecção pelo CDV pode ser bifásica, com picos aos cinco e aos 14 dias pós-infecção (Appel, 1969).

Os sinais clínicos mais óbvios da CC, que levam o proprietário a encaminhar o animal ao atendimento, são manifestados após a infecção 
do tecido epitelial, que se inicia geralmente no $14^{\circ}$ dia pós-infecção (Appel, 1969), o que pode dificultar o registro dessa alteração em levantamentos aleatórios. Da mesma forma, Moro (2001), após infecção experimental com a estirpe neurovirulenta Snyder Hill, observou hipertermia apenas em um animal. Estudos comprovaram que a indução de hipertermia em camundongos experimentalmente infectados com o vírus do sarampo foi um importante fator para eliminação do vírus devido ao aumento da produção da proteína Hsp 72.

Essa proteína possui diversas funções no metabolismo de outras proteínas, modulando a expressão gênica do RNA viral (Carsillo et al., 2006). Nesse sentido, acredita-se que a hipertermia seja um importante aliado contra a persistência do vírus no SNC e que, portanto, seja um sinal clínico pouco frequente em animais com sinais neurológicos.

Os sinais neurológicos foram variados (Tab. 4). Independentemente da localização no SNC, o vírus pode lesar a substância cinzenta e a substância branca, resultando em uma variedade de sinais neurológicos difusos ou focais, agudos ou crônicos e progressivos (Tipold et al., 1992; Amude et al., 2007). Os sinais neurológicos observados com maior frequência e com diferença estatística significativa $(\mathrm{P}<0,05) \mathrm{em}$ relação aos outros sinais foram: déficit motor (72\%) e mioclonia (70\%), assim como os achados de Tudury et al. (1997); Amaral (2007); Amude et al. (2007) e Silva et al. (2007). O déficit motor é um sinal inespecífico e envolve a participação de diversos componentes neuroanatômicos.

Como o vírus infecta diversas regiões do sistema nervoso, é de se esperar que a maioria dos animais manifeste a disfunção motora (Tipold et al., 1992; Martella et al., 2008). A mioclonia é uma das manifestações neurológicas mais frequentemente observadas na CC (Tipold et al., 1992; Headley et al., 1999; Silva et al., 2007), assim como foi observado neste estudo. Não se sabe qual é o papel do vírus nessa manifestação, mas há a hipótese de que ocorra uma desordem funcional em núcleos dos NMI ou nos núcleos basais no córtex prosencefálico (Lahunta et al., 2015).
Tabela 4. Prevalência dos sinais neurológicos observados em 76 cães naturalmente infectados com o vírus da cinomose canina

\begin{tabular}{|c|c|}
\hline Sinal clínico & $\begin{array}{l}\text { TR FCE }(+) \\
n=76(100 \%)\end{array}$ \\
\hline Déficit motor & $55(72 \%)^{\mathrm{a}}$ \\
\hline Mioclonia & $53(70 \%)^{\mathrm{a}}$ \\
\hline Alteração de estado mental & $42(55 \%)^{\mathrm{a}}$ \\
\hline $\begin{array}{l}\text { Crise epiléptica (focal ou } \\
\text { generalizada) }\end{array}$ & $26(34 \%)^{\mathrm{c}}$ \\
\hline Hiperpatia medular & $20(29 \%)^{\mathrm{e}, \mathrm{c}}$ \\
\hline Ataxia & $15(20 \%)^{\text {bce }}$ \\
\hline Estrabismo posicional ventral & $11(14 \%)^{\text {be }}$ \\
\hline Vocalização & $9(12 \%)^{\text {bd }}$ \\
\hline Desvio de cabeça & $8(10 \%)^{b d}$ \\
\hline $\begin{array}{l}\text { Diminuição dos reflexos } \\
\text { miotáticos }\end{array}$ & $4(5 \%)^{\mathrm{df}}$ \\
\hline Nistagmo & $3(4 \%)^{\mathrm{df}}$ \\
\hline Andar em círculos & $2(3 \%)^{\mathrm{f}}$ \\
\hline \multicolumn{2}{|c|}{$\begin{array}{l}\text { TR FCE = Teste rápido de imunocromatografia do } \\
\text { fluido cerebroespinhal. } \\
\text { Valores seguidos de letras distintas diferen } \\
\text { estatisticamente entre si pelo teste de qui-quadrado } \\
\text { com valor de } \mathrm{P}<0,05 \text {. }\end{array}$} \\
\hline
\end{tabular}

A avaliação imunocromatográfica demonstrou que, nos pacientes com sinais neurológicos, 76 animais (100\%) apresentaram resultado positivo nas amostras de FCE e 51 (67\%) apresentaram resultado positivo nas amostras de esfregaço conjuntival (Tab. 5). A comparação entre as amostras mostrou valores significativamente diferentes $(\mathrm{P}<0,0001)$ quanto à sensibilidade em detectar o CDV.

Segundo o protocolo do fabricante, a sensibilidade e a especificidade diagnóstica do teste utilizando amostras do raspado conjuntival, independentemente dos sinais clínicos, são altas, atingindo valores de $98,9 \%$ e $97,7 \%$, respectivamente. Diferentemente, Pereira (2010) observou sensibilidade de $86 \%$ e especificidade de $100 \%$ em amostras de FCE em animais com sinais clínicos e/ou neurológicos. No presente estudo, comparou-se, pela primeira vez, a eficácia do teste realizado com esfregaços conjuntivais e FCE em animais com sinais neurológicos associados ou não aos sinais sistêmicos.

Observou-se elevado índice de falso-negativos nas amostras conjuntivais, corroborando os resultados de Curti et al. (2012). Tais achados podem estar relacionados ao período de permanência do antígeno viral no tecido epitelial 
e ao momento em que o teste é realizado. Estudos com imunofluorescência identificaram que o antígeno é detectado até três semanas após a infecção, antes de desaparecer dos tecidos epiteliais (Jozwik e Frymus, 2005; Braz, 2009). Com isso, como o vírus possui um período de incubação de uma a quatro semanas, que pode chegar até quatro meses, aqueles animais que apresentarem sinais clínicos crônicos poderão ser negativos na imunocromatografia em amostras do raspado conjuntival, já que o antígeno pode ter desaparecido dos tecidos epiteliais (Jozwik e Frymus, 2005).

$\mathrm{Na}$ análise do FCE, a principal alteração observada foi a proteinorraquia (Tab. 6) $(\mathrm{P}<0,05)$, assim como observado por Tudury e colaboradores (1997). O aumento de proteína é um indicador de alteração no SNC e ocorre devido ao aumento da permeabilidade da BHE e/ou da produção intratecal de imunoglobulinas. Outros dois achados importantes observados foram a pleocitose e o aumento da quantidade de hemácias. Neste estudo, 100\% dos animais que apresentaram pleocitose tiveram o predomínio de linfócitos nas amostras. Segundo Platt e Garosi (2012), as amostras que apresentam predomínio de linfócitos, acima de 50\% das células nucleadas, são caracterizadas como pleocitose linfocítica.
Tabela 5. Comparação do teste de imunocromatografia para pesquisa de antígeno realizado em amostras de fluido cerebroespinhal e de esfregaço conjuntival de 76 cães com sinais clínico-neurológicos devido à infecção natural pelo vírus da cinomose

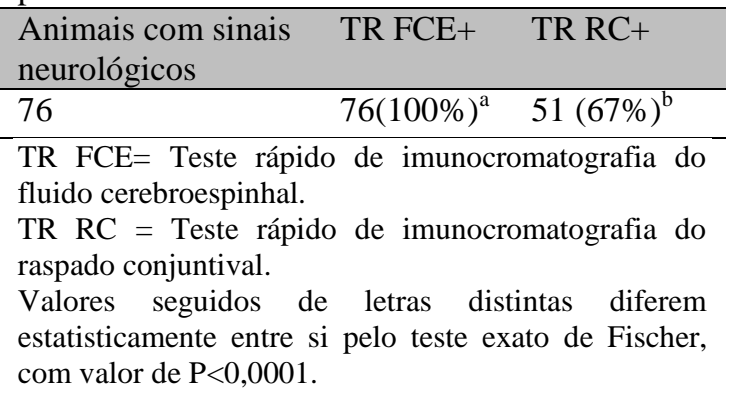

A pleocitose linfocítica com menos de 50 células/ $\mu \mathrm{L}$ é uma das características do FCE mais observadas em animais com CC (Amude et al., 2006), assim como foi observado neste estudo. A presença de hemácias indica contaminação no momento da coleta ou aumento da permeabilidade da BHE. Em casos de contaminação, a contagem de hemácias, geralmente, fica acima de 500 células $/ \mu \mathrm{L}$. No presente estudo, foram observados valores de, no máximo, 100 células $/ \mu \mathrm{L}$, o que, associado ao aumento de proteína, sugere aumento da permeabilidade da BHE.

Tabela 6. Principais alterações do fluido cerebroespinhal de 16 cães infectados com o vírus da cinomose canina

\begin{tabular}{ll}
\hline Alterações & $\mathrm{N}=16$ \\
\hline Proteinorraquia $(>20 \mathrm{mg} / \mathrm{dL})$ & $13(81 \%)^{\mathrm{b}}$ \\
Pleocitose $(>8$ células/ $\mu \mathrm{L})$ & $7(43 \%)^{\mathrm{a}}$ \\
Linfócitos acima de $50 \%$ & $7 / 7(100 \%)$ \\
Aumento da concentração de hemácias $(>0)$ & $7(56 \%)^{\mathrm{a}}$ \\
$\mathrm{CTCN}>50$ células/ $\mu \mathrm{L}$ & $1(6,25 \%)^{\mathrm{c}}$ \\
\hline
\end{tabular}

Valores seguidos de letras distintas diferem estatisticamente entre si pelo teste de qui-quadrado, com valor de $\mathrm{P}<0,05$. CTCN (contagem total de células nucleadas).

\section{CONCLUSÕES}

Este estudo epizootiológico caracterizou o comportamento e particularidades clínicas do CDV que podem auxiliar no reconhecimento e no tratamento precoce da infecção, principalmente quando associado ao teste imunocromatográfico com amostras do FCE.

\section{REFERÊNCIAS}

AMUDE, A.M.; ALFIERI, A.A.; ALFIERI, A.F. Antemortem diagnosis of CDV infection by RTPCR in distemper dogs with neurological deficits without the typical clinical presentation. Vet. Res. Commun., v.30, p.679-687, 2006. 
AMUDE, A.M.; CARVALHO, G.A.; ALFIERI, A.A. et al. Virus isolation and molecular characterization of canine distemper virus from a mature dog with multifocal encephalomyelitis. Braz. J. Microbiol., v.38, p.354-356, 2007.

APPEL, M.J.G. Pathogenesis of canine distemper. Am. J. Vet. Res, v.30, p.1167-1182, 1969

APPEL, M.J.G.; GILLESPIE, J.H. Canine distemper virus. Virol. Monogr., v.11, p.1-96, 1972.

BAUMGÄRTNER, W.; ORVELL, C.; REINACHER, M. Naturally occurring canine distemper virus encephalitis: distribution and expression of viral polypeptides in nervous tissues. Acta Neuropathol, v.78, p.504-512, 1989.

BRAZ, G.F. Padronização e teste da técnica de imunofluorescência direta para o diagnóstico da cinomose canina. 2009. 43f. Dissertação (Mestrado em Ciência Animal) - Universidade Federal de Minas Gerias.

BUDASZEWSKI, R.F.; PINTO, L.D.; WEBER, M.N. et al. Genotyping of canine distemper virus strains circulating in Brazil from 2008 to 2012. Virus Res., v.180, p.76-83, 2014.

CARSILlO, T.; TRAYLOR, Z.; CHOI, C. et al. Hsp72, a host determinant of measles virus neurovirulence. J. Virol., v.80, p.11031-11039, 2006.

CURTI, M.C.; ARIAS, M.V.B.; ZANUTTO, M.S. Avaliação de um kit imunoensaio cromatográfico para detecção do antígeno do virus da cinomose em cães com sinais sistêmicos ou neurológicos da doença. Semina: Ciências Agrárias, v.33, n.6, p. 2383-2390, 2012.

DAY, M.J.; HORZINEK, M.C.; SCHULTZ, R.D. et al. WSAVA guidelines for the vaccination of dogs and cats. J. Small Anim. Pract., v.51, p.1-32, 2016.

DEZENGRINI, R.; WEIBLEN, R.; FLORES, E.F. Soroprevalência das infecções por parvovírus, adenovírus, coronavírus canino e pelo vírus da cinomose em cães de Santa Maria, Rio Grande do Sul, Brasil. Ciênc. Rural, v.37, p.183-189, 2007.
GOUVEIA, A.M.G.; MAGALHÃES, H.H.; RIBEIRO, A.L. Cinomose canina: ocorrência em animais vacinados e distribuição por faixa etária. Arq. Bras. Med. Vet. Zootec., v.39, p.539-545, 1987.

GREENE, C.E.; VANDEVELDE, M. Canine distemper. In: GREENE, C.E. Infectious disease of the dog and cat. Philadelphia: Saunders Elsevier, 2012, p.25-41.

HASS, R.; JOHANN, J.M.; CAETANO, C.F. et al. Níveis de anticorpos contra o vírus da cinomose canina e o parvovírus canino em cães não vacinados e vacinados. Arq. Bras. Med. Vet. Zootec., v.60, p.270-274, 2008.

HEADLEY, S.A.; GRAÇA, D.L.; COSTA, M.M. ET AL. Canine distemper virus infection with secondary Bordetella bronchiseptica pneumonia in dogs. Ciência Rural, v.29, n.4, p.741-743, 1999.

HEADLEY, S.A.; AMUDE, A.M.; ALFIERI, A.F. et al. Epidemiological features and the neuropathological manifestations of canine distemper virus-induced infections in Brazil: a review. Semin. Ciênc. Agr., v.33, p.1945-1978, 2012.

HEADLEY, S.A.; AMUDE, A.M.; ALFIERI, A.F. et al. Molecular detection of canine distemper virus and the immunohistochemical characterization of the neurologic lesions in naturally occurring old dog encephalitis. J. Vet. Diagn. Invest., v.21, p.588-597, 2009.

HEADLEY, S.A.; GRAÇA, D.L. Canine distemper: epidemiological findings of 250 cases. Braz. J. Res. Anim. Sci., v.37, p.136-140, 2000.

IWATSUKI, K.; MIYASHITA, N.; YOSHIDA, E. et al. Molecular and phylogenetic analyses of the haemagglutinin $(\mathrm{H})$ proteins of field isolates of canine distemper virus from naturally infected dogs. J. Gen. Virol., v.78, p.373-380, 1997.

JOZWIK, A.; FRYMUS, T. Comparasion of the immunofluorescence assay with RT-PCR and nested PCR in the diagnosis of canine distemper. Vet Res Commun, v.29, p.347-359, 2005.

KOUTINAS, A.F.; POLIZOPOULOU, Z.S.; BAUMGAERTNER, W. et al. Relation of clinical signs to pathological changes in 19 cases of canine distemper encephalomyelitis. J. Comp. Path., v.126, p.47-56, 2002. 
KRAKOWKA, S.; KOESTNER, A. Agerealated susceptibility to infection with canine distemper virus in gnotobiotic dogs. J. Infec. Dis., v.134, p.629-632, 1976.

LAHUNTA, A.; GLASS, E.; KENT, M. Veterinary neuroanatomy and clinical neurology. 4.ed. St Louis: Saunders Elsevier, 2015. 587p.

MARTELLA, V.; ELIA, G.; BUONAVOGLIA, C. Canine distemper virus. Vet Clin Small Anim., v.38, p.787-797, 2008.

MORO, L. Apoptose na patogenia da cinomose canina. 2001. 192f. Tese (Doutorado em Patologia) - Faculdade de Medicina, Universidade Federal de Minas Gerais, Belo Horizonte, MG.

PANZERA, Y.; CALDERÓN, M.G.; SARUTE, N. et al. Evidence of two co-circulating genetic lineages of canine distemper virus in South America. Virus Res., v.163, p.401-404, 2012.

PANZERA, Y.; SARUTE, N.; IRAOLA, G. et al. Molecular phylogeography of canine distemper virus: geographic origin and global spreading. Mol. Phylogenet. Evol., v.92, p.147$154,2015$.

PEREIRA, F.B. Comparação de métodos de diagnósticos para a cinomose canina, com ênfase nas alterações oculares. 2010.93p. Dissertação (Mestrado em Ciências Veterinárias) - Universidade Federal do Paraná, Curitiba.
PLATT, S.; GAROSI, L. Small animal neurological emergencies. London: Manson Publishing, 2012. 672p.

SILVA, M.C.; FIGHERA, R.A., MAZZANTI, A. et al. Neuropatologia da cinomose canina: 70 casos (2005-2008). Pesqui. Vet. Bras., v.29, p.643-652, 2009.

SILVA, M.C.; FIGHERA, R.A.; BRUM, J.S. et al. Aspectos clinicopatológicos de 620 casos neurológicos de cinomose em cães: clinicopathological features in 620 neurological cases of canine distemper. Pesqui. Vet. Bras., v.27, p.215-220, 2007.

SONNE, L.; OLIVEIRA, E.C.; PESCADOR, C.A.; et al. Achados patológicos e imunohistoquímicos em cães infectados naturalmente pelo vírus da cinomose canina. Pesqui. Vet. Bras., v.29, p.143-149, 2009.

TIPOLD, A.; VANDEVELDE, M.; JAGGY, A. Neurologic manifestations of canine distemper virus infection. J. Small Anim. Pract., v.33, p.466-470, 1992.

TUDURY, E.A.; ARIAS, M.V.B.; BRACARENSE, A.P.F.L. et al. Observações clínicas e laboratoriais em cães com cinomose nervosa. Ciênc. Rural, v.27, p.229-235, 1997. 